\title{
Influence of Substitution on Structure and Magnetic Properties of Rapidly Quenched $\mathrm{Fe}_{86} \mathrm{~B}_{14}$ Alloy
}

\author{
L. Hawelek ${ }^{a, *}, \mathrm{P} . \mathrm{WlodarczyK}^{a}, \mathrm{M} \cdot \mathrm{Polak}^{a}, \mathrm{P} \cdot \mathrm{ZaCkiewicz}^{a}, \mathrm{~T} \cdot \mathrm{WARski}^{a}, \mathrm{~A} \cdot \mathrm{Wojcik}^{b}$, \\ W. MAZIARZ ${ }^{b}$ AND A. KOLANO-BURIAN ${ }^{a}$ \\ ${ }^{a}$ Łukasiewicz Research Network, Institute of Non-Ferrous Metals, ul. Sowinskiego 5, 44-100 Gliwice, Poland \\ ${ }^{b}$ Institute of Metallurgy and Materials Science Polish Academy of Sciences, \\ 25 Reymonta str., 30-059 Krakow, Poland
}

\begin{abstract}
Influence of $\mathrm{Si}$ and $\mathrm{Co}$ substitution for $\mathrm{Fe}$ in rapidly quenched $\mathrm{Fe}_{86} \mathrm{~B}_{14}$-type alloy (metallic ribbons form) on the crystallization temperature, crystal structure and magnetic properties are reported for three different metallic glasses: $\mathrm{Fe}_{86} \mathrm{~B}_{14}, \mathrm{Fe}_{84} \mathrm{Si}_{2} \mathrm{~B}_{14}$, and $\mathrm{Fe}_{80} \mathrm{Co}_{4} \mathrm{Si}_{2} \mathrm{~B}_{14}$. At first, the onset temperatures of crystallization process were determined for both bcc-Fe (primary crystallization) and bct-Fe 3 B phase types (secondary crystallization) by calorimetric measurements with use of $10^{\circ} \mathrm{C} / \mathrm{min}$ heating rate. On the basis of obtained results, the conventional heat treatment process (with heating rate $10^{\circ} \mathrm{C} / \mathrm{min}$ and subsequent isothermal annealing) for wound toroidal cores has been optimized in order to obtain best soft magnetic properties (minimum value of coercivity $H_{c}$ and magnetic core loss $\left.P_{s}\right)$ at frequency $f=50 \mathrm{~Hz}$. For the optimal annealed samples the complex magnetic permeability $\left(\mu^{\prime}, \mu^{\prime \prime}\right)$ was measured, in the frequency range $10^{4}-10^{8} \mathrm{~Hz}$. Finally, the stage of the crystallization process was identified by the use of X-ray diffraction (XRD) method and the transmission electron microscopy (TEM) observations.
\end{abstract}

DOI: 10.12693/APhysPolA.137.811

PACS/topics: soft magnetic materials, metallic glass, magnetic properties

\section{Introduction}

In the last few years, new generation of high saturation induction $\left(B_{s}>1.75 \mathrm{~T}\right)$ nanocrystalline alloy systems including $\mathrm{FeBCu}[1], \mathrm{FeSiBCu}[2], \mathrm{FeSiBPCu}[3]$, and FeSiBPCCu [4] were successfully developed. The maximum values of $B_{s}$ were obtained for $\mathrm{Cu}$ containing alloys, in which nanocrystallization process was governed by conventional heating with rate $10-40^{\circ} \mathrm{C} / \mathrm{min}$, and subsequent isothermal annealing. In 2018, Suzuki et al. [5] showed that for $\mathrm{Cu}$-free binary $\mathrm{Fe}_{86} \mathrm{~B}_{14}$ alloy the ultrarapid annealing process (heating rate $>100^{\circ} \mathrm{C} / \mathrm{s}$ ) is sufficient to obtain $B_{s} \simeq 1.9-1.92 \mathrm{~T}$, as well as relatively low $H_{c} \simeq 4.6-6.7 \mathrm{~A} / \mathrm{m}$. According to T. Liu et al. [4], for the conventional annealing the appropriate addition of $\mathrm{Cu}$ allows to synchronize the crystallization, which is essential for excellent magnetic properties. Authors have demonstrated that during annealing process the microstructure goes through three stages: stress relief, nanocrystallization, and second phase precipitation. It has been also shown, that for the $\mathrm{Cu}$-free alloy the difficult nucleation process leads to insufficient nucleation sites resulting in excessive grain growth [6]. The optimal magnetic properties were obtained by the annealing in the pre-nanocrystallization — stress relief stage during the relaxation process [7].

\footnotetext{
* corresponding author; e-mail lukasz.hawelek@imn.gliwice.pl
}

The effect of substitution of +2 at. $\%$ of Si for Fe, and further of +4 at. $\%$ of $\mathrm{Co}$ for $\mathrm{Fe}$, in the initially $\mathrm{Cu}$-free $\mathrm{Fe}_{86} \mathrm{~B}_{14}$ binary alloy has been shown in the present work, based on magnetic properties: $B(H)$ relationship, $P_{s}$, and $\left(\mu^{\prime}, \mu^{\prime \prime}\right)$. The conventional heat treatment process of $\mathrm{Fe}_{86} \mathrm{~B}_{14}, \mathrm{Fe}_{84} \mathrm{Si}_{2} \mathrm{~B}_{14}$, and $\mathrm{Fe}_{80} \mathrm{Co}_{4} \mathrm{Si}_{2} \mathrm{~B}_{14}$ alloys was successfully optimized. Then, the crystal structure of the annealed samples was verified by X-ray diffraction method and transmission electron microscopy observations. The results will be used to optimize newly developed ultra-rapid annealing process.

\section{Experimental}

The amorphous alloys with nominal compositions $\mathrm{Fe}_{86} \mathrm{~B}_{14}, \mathrm{Fe}_{84} \mathrm{Si}_{2} \mathrm{~B}_{14}$, and $\mathrm{Fe}_{80} \mathrm{Co}_{4} \mathrm{Si}_{2} \mathrm{~B}_{14}$, in the form of ribbons with a $33-35 \mu \mathrm{m}$ thickness and $6.5 \mathrm{~mm}$ width were obtained by melt spinning technique (at $30 \mathrm{~m} / \mathrm{s}$ $\mathrm{Cu}$ wheel speed). To achieve the optimal magnetic parameters (min. value of $H_{c}$ and $P_{s}$ at $50 \mathrm{~Hz}$, and $B_{s}$ ), the toroidal cores were isothermally annealed for $20 \mathrm{~min}$ in vacuum furnace $\left(5 \times 10^{-4}\right.$ mbar $)$ at different temperatures from $300{ }^{\circ} \mathrm{C}$ to $420^{\circ} \mathrm{C}$. Amorphousness of the as-spun and annealed ribbons were studied by X-ray diffraction (XRD) at room temperature using a Rigaku MiniFlex 600 diffractometer $\left(\mathrm{CuK}_{\alpha}\right.$ radiation). The crystallization processes have been monitored by the differential scanning calorimetry (DSC) with a heating rate of $10^{\circ} \mathrm{C} / \mathrm{min}$ using thermal analyzer Netzsch STA $449 \mathrm{~F} 3$. Transmission electron microscopy (TEM) images in the bright-field (BF) mode, and selected area diffraction patterns (SADPs) were recorded using Tecnai G2 F20 (200 kV) electron microscope. The Remacomp 
C-1200 (MAGNET-PHYSIK Dr. Steingroever GmbH) magnetic measurement system was used to determine $B(H)$ and $P_{s}$. The complex magnetic permeability in the frequency range $10^{4}-10^{8} \mathrm{~Hz}$ at room temperature of the toroidal cores was measured using impedance analyzer Agilent 4294A.

\section{Results and discussion}

The fully amorphous state was verified by XRD, and no evidence of surface crystallization has been found. The DSC curves are shown in Fig. 1. Two exothermal crystallization peaks are visible in the presented thermograms. The first peak (at $T_{x 1}$ ) corresponds to the $\alpha$-Fe crystallization process (bcc-Fe type structure), while the second (at $T_{x 2}$ ) to the bct- $\mathrm{Fe}_{3} \mathrm{~B}$ type phase crystallization process. The calculated difference between the onset temperatures of two peaks $\Delta T=T_{x 2}-T_{x 1}$ is equal to $\sim 103{ }^{\circ} \mathrm{C}$ for $\mathrm{Fe}_{86} \mathrm{~B}_{14}, \sim 83^{\circ} \mathrm{C}$ for $\mathrm{Fe}_{84} \mathrm{Si}_{2} \mathrm{~B}_{14}$, and $\sim 99^{\circ} \mathrm{C}$ for $\mathrm{Fe}_{80} \mathrm{Co}_{4} \mathrm{Si}_{2} \mathrm{~B}_{14}$ alloy. The shift of both $T_{x 1}$ and $T_{x 2}$ to the higher values for alloys with higher silicon content indicates the increase of the thermal stabilities of the amorphous alloys against crystallization, and is consistent with the previous observations [8]. The cobalt substitution for iron decreases value of $T_{x 1}$ from $414^{\circ} \mathrm{C}$ to $402^{\circ} \mathrm{C}$, in turn slightly increases value of $T_{x 2}$ onset temperature from $497^{\circ} \mathrm{C}$ to $501^{\circ} \mathrm{C}$. This effect of Co substitution is well known in the literature [7].

By investigating the effect of annealing temperature on magnetic properties it was possible to determine optimum annealing temperature. The desirable minimal values of $H_{c}$ and $P_{s}$ were obtained for the following annealing temperatures $T_{a}: 320^{\circ} \mathrm{C}$ for $\mathrm{Fe}_{86} \mathrm{~B}_{14}, 330^{\circ} \mathrm{C}$ for $\mathrm{Fe}_{84} \mathrm{Si}_{2} \mathrm{~B}_{14}$, and $330^{\circ} \mathrm{C}$ for $\mathrm{Fe}_{80} \mathrm{Co}_{4} \mathrm{Si}_{2} \mathrm{~B}_{14}$. The measured hysteresis loops are presented in Fig. 2. The magnetic parameters such as: $B_{s}, H_{c}$, remanence $B_{r}$, calculated $P_{s}$ values, and squareness factor $S_{f}=B_{r} / B_{s} \times 100 \%$ have been gathered in Table I. The optimized $T_{a}$ values are much smaller than $T_{x 1}$. The difference between $T_{x 1}$

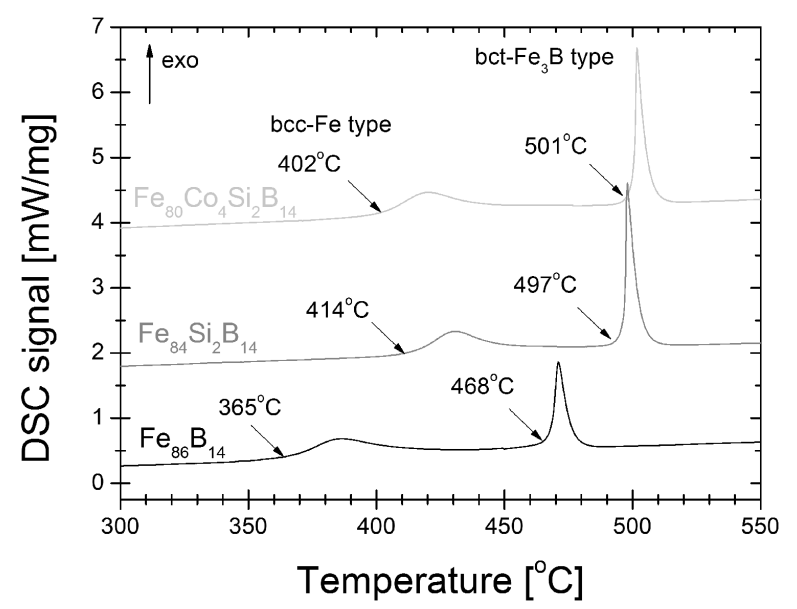

Fig. 1. DSC measurement curves of samples annealed with heating rate $10^{\circ} \mathrm{C} / \mathrm{min}$.

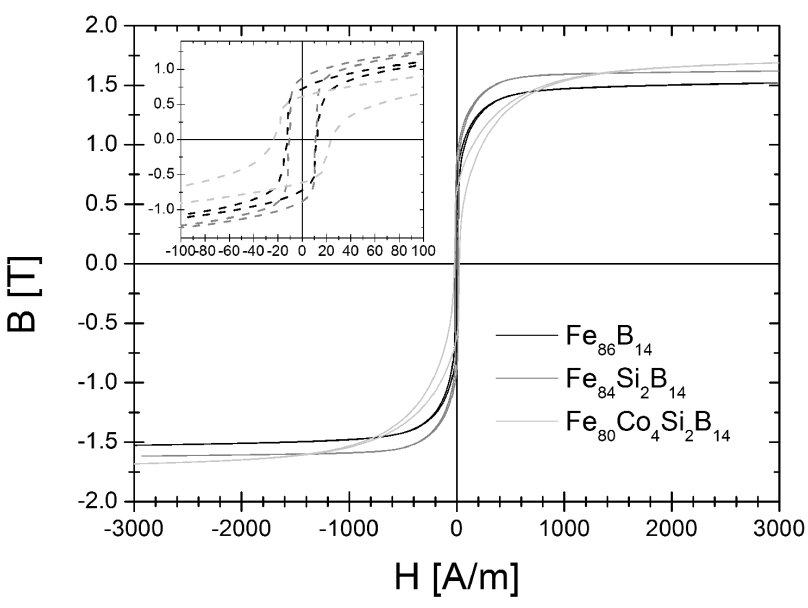

Fig. 2. Hysteresis loops for annealed samples.

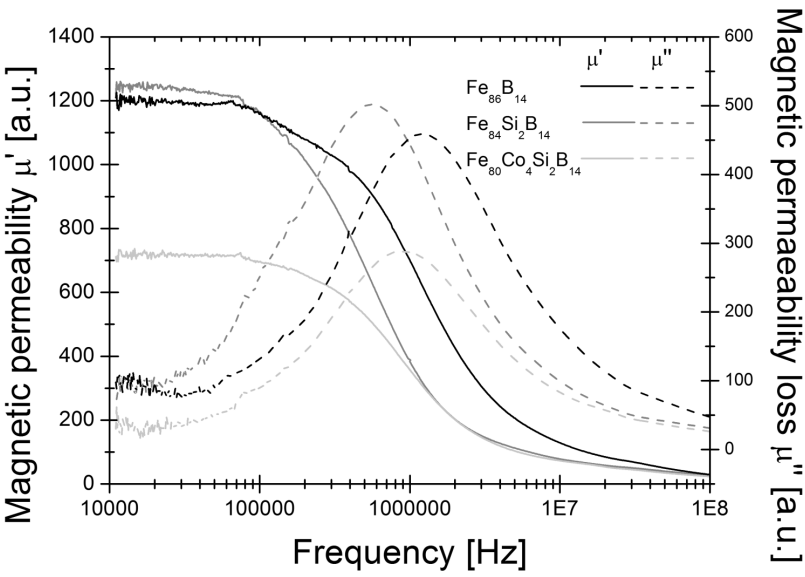

Fig. 3. 3: Magnetic permeability $\mu^{\prime}$ and magnetic permeability loss $\mu^{\prime \prime}$ dependence in the function of frequency $10^{4}-10^{8} \mathrm{~Hz}$ for annealed samples.

\section{TABLE I}

Magnetic parameters: magnetic saturation $B_{s}$, coercivity $H_{c}$, remanence $B_{r}$, core losses $P_{s}$, and squareness factor $S_{f}=\left(B_{r} / B_{s}\right) \cdot 100 \%$.

\begin{tabular}{l|c|c|c|c|c}
\hline \hline \multicolumn{1}{c|}{ Sample } & $\begin{array}{c}B_{s} \\
{[\mathrm{~T}]}\end{array}$ & $\begin{array}{c}B_{r} \\
{[\mathrm{~T}]}\end{array}$ & $\begin{array}{c}H_{c} \\
{[\mathrm{~A} / \mathrm{m}]}\end{array}$ & $\begin{array}{c}P_{s} \\
{[\mathrm{~W} / \mathrm{kg}]}\end{array}$ & $\begin{array}{c}S_{f} \\
{[\%]}\end{array}$ \\
\hline \hline $\mathrm{Fe}_{86} \mathrm{~B}_{14}$ & 1.52 & 0.724 & 12.6 & 0.68 & 47.6 \\
$\mathrm{Fe}_{84} \mathrm{Si}_{2} \mathrm{~B}_{14}$ & 1.62 & 0.878 & 10.8 & 0.53 & 54.2 \\
$\mathrm{Fe}_{80} \mathrm{Co}_{4} \mathrm{Si}_{2} \mathrm{~B}_{14}$ & 1.69 & 0.61 & 23.6 & 1.8 & 36.1
\end{tabular}

and $T_{a}$, defined as $T_{d}=T_{x 1}-T_{a}$, equals $45^{\circ} \mathrm{C}, 84^{\circ} \mathrm{C}$, and $72{ }^{\circ} \mathrm{C}$, for $\mathrm{Fe}_{86} \mathrm{~B}_{14}, \mathrm{Fe}_{84} \mathrm{Si}_{2} \mathrm{~B}_{14}$, and $\mathrm{Fe}_{80} \mathrm{Co}_{4} \mathrm{Si}_{2} \mathrm{~B}_{14}$, respectively. As it was shown in [4] for $\mathrm{Cu}$-free alloys there is only one optimal annealing temperature that should be found at the early stage of nanocrystallization process, just after so called "stress relief" stage.

In case of $\mathrm{Fe}_{86} \mathrm{~B}_{14}$ the $H_{c}$ value of reaches $12.6 \mathrm{~A} / \mathrm{m}$, and $P_{s}=0.68 \mathrm{~W} / \mathrm{kg}$. The value of $B_{s}$ at $3000 \mathrm{~A} / \mathrm{m}$ is $1.52 \mathrm{~T}$, while $B_{r}=0.724$. Thus, the calculated 


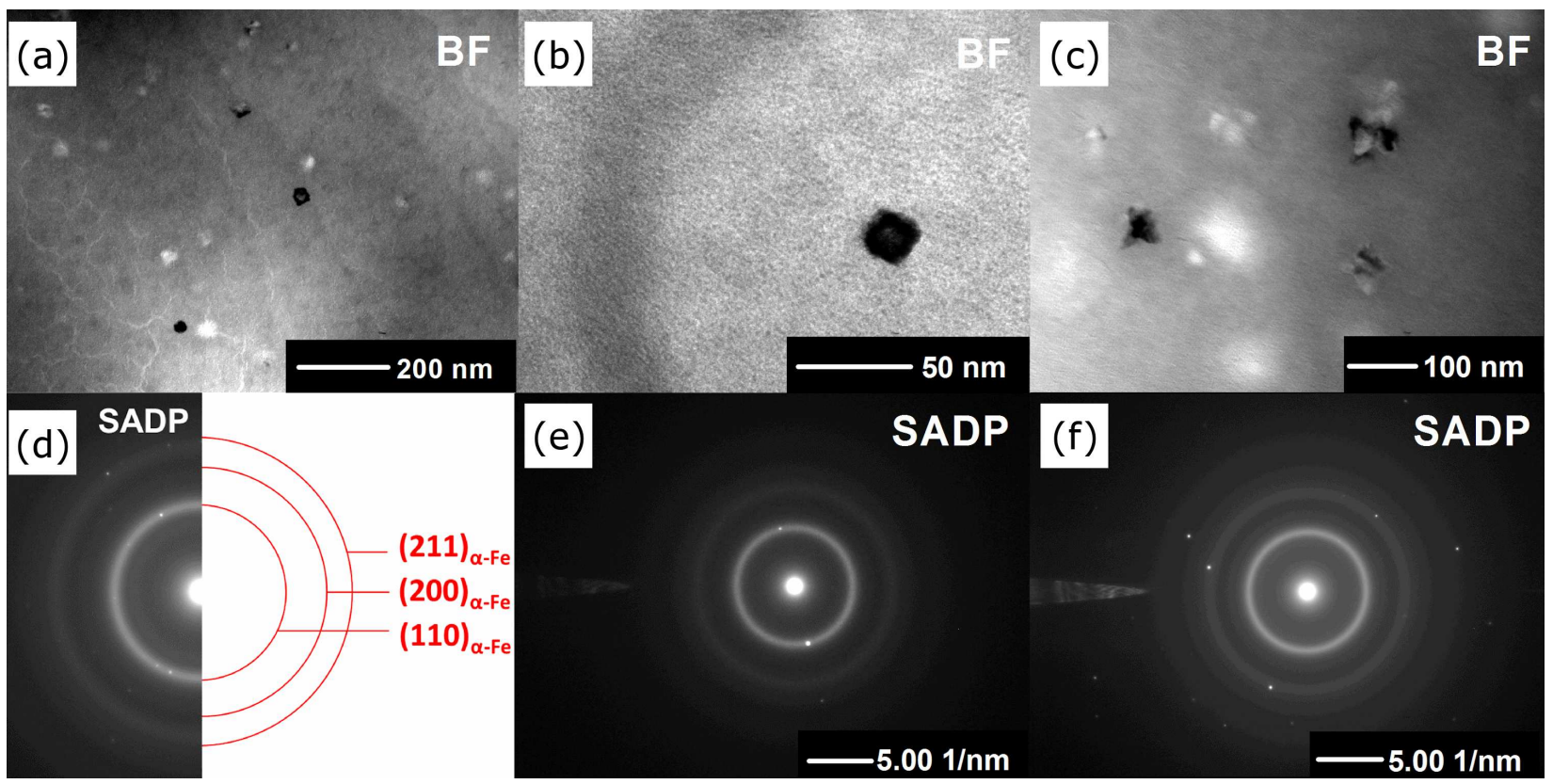

Fig. 4. TEM images of annealed samples: (a) $\mathrm{BF}$ of $\mathrm{Fe}_{86} \mathrm{~B}_{14}$, (b) $\mathrm{BF}$ of $\mathrm{Fe}_{84} \mathrm{Si}_{2} \mathrm{~B}_{14}$, (c) $\mathrm{BF}$ of $\mathrm{Fe}_{80} \mathrm{Co}_{4} \mathrm{Si}_{2} \mathrm{~B}_{14},(\mathrm{~d}$ ) SADP of $\mathrm{Fe}_{86} \mathrm{~B}_{14}$, (e) SADP of $\mathrm{Fe}_{84} \mathrm{Si}_{2} \mathrm{~B}_{14}$, (f) SADP of $\mathrm{Fe}_{80} \mathrm{Co}_{4} \mathrm{Si}_{2} \mathrm{~B}_{14}$.

$S_{f}$ is $47.6 \%$. In case of $\mathrm{Fe}_{84} \mathrm{Si}_{2} \mathrm{~B}_{14}$ alloy $H_{c}$ decreases to $10.8 \mathrm{~A} / \mathrm{m}, P_{s}$ decreases to $0.53 \mathrm{~W} / \mathrm{kg}$, while $B_{s}$ increases up to $1.62 \mathrm{~T}$, as well as $S_{f}$ to $54.2 \%$. Similar effect of soft magnetic enhancement by limited addition of Si was observed by Ohta et al. [9]. For Co containing sample, the $B_{s}$ value increases up to $1.69 \mathrm{~T}$ at $3000 \mathrm{~A} / \mathrm{m}$, while unfortunately $H_{c}$ and $P_{s}$ also increase to $23.6 \mathrm{~A} / \mathrm{m}$ and $1.8 \mathrm{~W} / \mathrm{kg}$, respectively. Together with deterioration of soft magnetic properties $S_{f}$ decreases to $36.1 \%$.

The frequency dependent $\mu^{\prime}$ and $\mu^{\prime \prime}$ permeabilities are gathered in Fig. 3. For binary Fe-B alloy $\mu^{\prime}$ reaches 1200 for $f=10^{4}-10^{5} \mathrm{~Hz}$, and the maximum value of losses $\mu^{\prime \prime}$ is observed at $10^{6} \mathrm{~Hz}$. The soft magnetic properties of Si substituted alloy are slightly enhanced. The value of $\mu^{\prime}$ has been increased to 1270 with maximum value of $\mu^{\prime \prime}$ shifted to $5 \times 10^{5} \mathrm{~Hz}$, which may suggest that the size of nanocrystals has been slightly increased compared to Fe-B alloy. For Co containing alloy, deterioration of soft properties is visible through the decrease of $\mu^{\prime}$ to the value $\mu^{\prime}=700$. The maximum of $\mu^{\prime \prime}$ is observed at $f=9 \times 10^{5} \mathrm{~Hz}$.

The first crystal structure verification of the annealed samples have been done by XRD method, and there were only very weak peaks emerging in the position of the $\alpha$-Fe phase. In fact, TEM observations in BF mode (Fig. 4a-c) and SADPs (Fig. 4d-f) for all samples proved the presence of $\alpha$-Fe nanocrystals of $\sim 25 \mathrm{~nm}$ in all samples. However the number of nanocrystals was very limited, and decreasing for single nanocrystals for $\mathrm{Fe}_{84} \mathrm{Si}_{2} \mathrm{~B}_{14}$ alloy, while increasing number of nanocrystals for Co containing alloy. Basing on TEM observations the stress relief/pre-nanocrystalization stage for all samples is visible. Low and high density amorphous states coexist with few number of nanocrystals, and such local atomic arrangement might be responsible for good magnetic properties.

\section{Conclusion}

The structural and magnetic properties of conventionally annealed $\mathrm{Fe}_{86} \mathrm{~B}_{14}, \mathrm{Fe}_{84} \mathrm{Si}_{2} \mathrm{~B}_{14}$ and $\mathrm{Fe}_{80} \mathrm{Co}_{4} \mathrm{Si}_{2} \mathrm{~B}_{14}$ alloys prepared by melt spinning have been investigated. The main conclusions are as follows:

The optimum $T_{a}$ values are much smaller than $T_{x 1}$. The difference $T_{x 1}-T_{a}$ is equal to: $45^{\circ} \mathrm{C}$ for $\mathrm{Fe}_{86} \mathrm{~B}_{14}$, $84^{\circ} \mathrm{C}$ for $\mathrm{Fe}_{84} \mathrm{Si}_{2} \mathrm{~B}_{14}$, and $72{ }^{\circ} \mathrm{C}$ for $\mathrm{Fe}_{80} \mathrm{Co}_{4} \mathrm{Si}_{2} \mathrm{~B}_{14}$. TEM BF images for annealed samples prove the existence of early stage of nanocrystallization process with limited numbers of $\alpha$-Fe nanocrystals $\sim 25 \mathrm{~nm}$. For $\mathrm{Fe}_{84} \mathrm{Si}_{2} \mathrm{~B}_{14}$ alloy the amorphous state is the most stable, and only single nanocrystals occur.

Annealed $\mathrm{Fe}_{84} \mathrm{Si}_{2} \mathrm{~B}_{14}$ alloy with the smallest nanocrystals content exhibits the best soft magnetic properties with $B_{s}=1.62 \mathrm{~T}, H_{c}=10.8 \mathrm{~A} / \mathrm{m}, P_{s}=0.53 \mathrm{~W} / \mathrm{kg}$, and highest $\mu^{\prime}=1200$ in the range of $10^{4}-10^{5} \mathrm{~Hz}$ with maximum value of $\mu^{\prime \prime}$ at $f=10^{6} \mathrm{~Hz}$.

The Co addition increases $B_{s}$ up to $1.69 \mathrm{~T}$, while deteriorates the soft magnetic properties: $H_{c}=23.6 \mathrm{~A} / \mathrm{m}$, $P_{s}=1.8 \mathrm{~W} / \mathrm{kg}$, and $\mu^{\prime}$ of $\sim 700$.

\section{Acknowledgments}

This work was co-financed by the National Centre for Research and Development Grant TECHMATSTRATEG No. 1/347200/11/NCBR/2017, the National Science Centre OPUS14 Grant no 2017/27/B/ST8/01601 and the internal source: IMN own studies, IMN project no. ST $/ 48 / 2019 / \mathrm{G}$. 


\section{References}

[1] M. Ohta, Y. Yoshizawa, Mater. Trans. 48, 2378 (2007).

[2] M. Ohta, Y. Yoshizawa, Appl. Phys. Lett. 91, 062517 (2007).

[3] A. Makino, T. Kubota, K. Yubuta, A. Inoue, A. Urata, H. Matsumoto, S. Yoshida, J. Appl. Phys. 109, 07A302 (2011)

[4] T. Liu, A. Wang, C. Zhao, S. Yue, X. Wang, C.T. Liu, Mater. Res. Bull. 112, 323 (2019).
[5] K. Suzuki, R. Parsons, B. Zang, K. Onodera H. Kishimoto, T. Shoji, A. Kato, J. Alloys Compd. 735, 613 (2018)

[6] P. Sharma, X. Zhang, Y. Zhang, A. Makino, Scr. Mater. 95, 3 (2015).

[7] C. Zhao, A. Wang, A. He, S. Yue, C. Chang, X. Wang, R. Li, J. Alloys. Compd. 659, 193 (2016).

[8] A.J. Kailath, A. Kumar, A. Mitra, Bull. Mater. Sci. 29, 127 (2006).

[9] M. Ohta, Y. Yoshizawa, Appl. Phys. Lett. 91, 062517 (2007). 